\title{
34 A CASE STUDY APPROACH TO EXAMINING SERVICE INFORMATION REQUIREMENTS
}

\author{
Rachel Cuthbert \\ Paris Pennesi \\ Duncan McFarlane \\ Distributed Information and Automation Laboratory \\ Department of Engineering \\ University of Cambridge \\ Cambridge, UK
}

\section{ABSTRACT}

In this paper, we propose a case study approach to examine and assess the information required to underpin services for particular industrial service offerings. The focus of this paper is on the means by which service information requirements may be extracted and understood, as opposed to on how service information requirements are subsequently used.

The term service information requirements refers to a set of information needed to support the delivery of a service to a customer. The area of service information requirements is a new, and a less researched, area compared with product information requirements. Service is important for both product and service delivering organizations as companies move toward the provision of integrated solutions. Within manufacturing, one of the most significant trends is toward servitization, in particular for high-value, complex goods, where the focus of the product and service providers is on the associated service delivered.

Information is important in service as a means of enhancing decisions. The information has no direct value, but the impact of improved information quality can reduce costs or enhance service decisions. In the context of product servicing, the information can provide details about the condition and usage of the product. In a service delivery context, information provides the specification of the customer to enable service delivery decisions to be made.

\section{Please use the following format when citing this chapter:}

Cuthbert, R., Pennesi, P., and McFarlane, D., 2008, in IFIP International Federation for Information Processing, Volume 267, Information Technology in the Service Economy: Challenges and Possibilities for the $21^{\text {st }}$ Century, eds. Barrett, M., Davidson, E., Middleton, C., and DeGross, J. (Boston: Springer), pp. 383-385. 


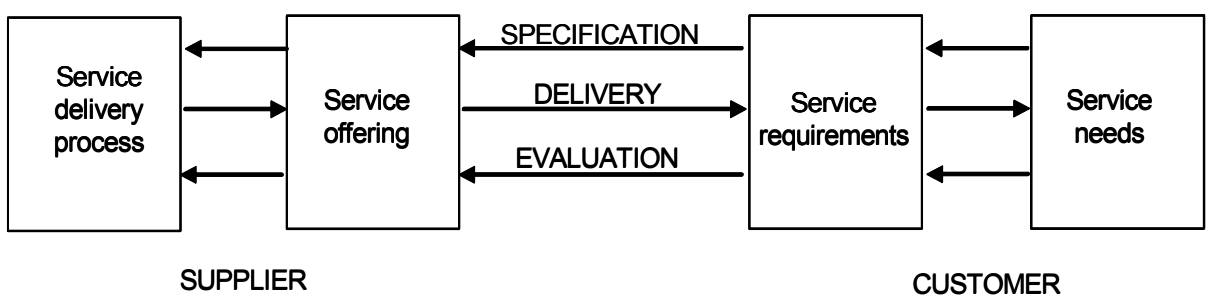

Figure 1. Service Information Model

This research proposes a process of obtaining service information requirements in order to determine the needs of the customer and to determine the information required for the supplier to deliver this service to the customer. To achieve this approach, we propose a service information model (see Figure 1).

The first stage of this approach is to identify the specification process or the information needed to translate the customer need into requirements in the form of a performance-based contract.

Having gained an understanding of the requirements of the service, the actual process for the delivery of the service is mapped to identify the information needed to deliver the service.

The evaluation stage determines the information needed to assess the service provided against that specified, and the means by which the measurements of service delivery are achieved.

Analysis of the approach should assess the role of information and its impact on the performance of the service delivery process as well as an understanding of the consequences of a variation in information quality throughout the requirements, delivery, and evaluation processes. From this analysis, two questions need to be answered.

(1) What is the impact of the information on the service performance?

(2) What is the current quality of the information?

The proposed approach to service information requirements collection, detailed in the paper, will test the effectiveness in determining the information requirements for service provision. This will be achieved through a series of cross-sector case studies. A further extension to this could assess the industry status of information requirements.

\section{About the Authors}

Rachel Cuthbert graduated in 2000 with an M.A. and M.Eng. in Engineering from Cambridge University with a specialization in fluid mechanics and thermodynamics. Following this, she successfully completed the Advanced Course in Design, Manufacture and Management (ACDMM, now ISMM) in 2001 at the Institute for Manufacturing, Cambridge University. She has gained significant industrial experience from her work in the chemical process and inkjet industries from research anf development, manufacturing, and supply chain roles. Rachel is a 
Chartered Engineer and a Member of the Institution of Mechanical Engineers (2004). She is a Research Associate in the Distributed Information and Automation Laboratory. Her current research focus is on service information requirements and service supply chains. Her e-mail address is rc443@eng.cam.ac.uk

Paris Pennesi obtained his Laurea in Electronic Engineering (2002) with honors from the Universita' degli Studi di Ancona, Italy, and his Ph.D. in Artificial Intelligent System (2006) from the Universita' Politecnica delle Marche. During the same period, he also created JEF, a consultancy company, and worked in several software and industrial projects with Italian SMEs. He held a visiting scholar appointment with the College of Engineering at Boston University, from September 2004 to December 2005. His current research interests lie in the fields of stochastic distributed systems and control, optimization and information architecture. The main application areas he is targeting include service supply chain, dynamic pricing, capacity management, inventory control, and multi-agent coordination. His e-mail address is pp300@eng.cam.ac.uk

Duncan McFarlane (University of Cambridge) has been Professor of Service and Support Engineering at the Cambridge University Engineering Department since 2006, and head of the Distributed Information and Automation Laboratory (DIAL) within the Institute for Manufacturing since 1995. He is currently the research lead on the BAE Systems Service and Support Engineering Programme at Cambridge, and founder of the Cambridge Service Systems Forum. He is also Research Director of the Aero ID Programme, involving 20 companies from the aerospace sector examining the role of ID systems within their operations. Until March 2007, he was Director of the Cambridge Auto ID Lab. Between 2000 and 2003, he was the European Research Director of the Auto-ID Center, a program that has driven the industrial adoption of RFID on a global scale. Since 2001, he has been a co-investigator in the EPSRC funded Innovative Manufacturing Research Centre based in the Institute for Manufacturing, currently investigating the role of information in complex asset tracking. He has been a principal investigator on a significant number of UK, EU, and industrially based research programs and now leads a research center of more than 20 researchers and doctoral students. His specific research interests can be summarized as valuing industrial information, information quality assessment, ID and sensor integration methods, distributed information architectures, lifecycle information management, distributed automation, and decision making and reconfigurability. Duncan has developed a research profile which straddles both technical and operations management issues and works closely with researchers in policy, strategy and operations areas. His e-mail address is dcm@eng.cam.ac.uk. 